\title{
ZnO Heteroepitaxy on Sapphire Using a Novel Buffer Layer of Titanium Oxide: Optoelectronic Behavior
}

\author{
Satoshi Yamauchi ${ }^{*}$, Yoh Imai ${ }^{2}$ \\ ${ }^{1}$ Department of Biomolecular Functional Engineering, Ibaraki University, Hitachi, Japan \\ ${ }^{2}$ Department of Electric and Electronic Engineering, Ibaraki University, Hitachi, Japan \\ Email: "ysatoshi@mx.ibaraki.ac.jp
}

Received April 16, 2013; revised May 21, 2013; accepted June 17, 2013

Copyright (C) 2013 Satoshi Yamauchi, Yoh Imai. This is an open access article distributed under the Creative Commons Attribution License, which permits unrestricted use, distribution, and reproduction in any medium, provided the original work is properly cited.

\begin{abstract}
Optoelectronic property of $\mathrm{ZnO}$ epitaxial layer grown by plasma-assisted epitaxy at temperature as low as $340^{\circ} \mathrm{C}$ using $\mathrm{Ti}_{2} \mathrm{O}_{3}$ buffer layer on a-sapphire were studied by low temperature photoluminescence at $10 \mathrm{~K}$ comparing to the layers on c-sapphire and a-sapphire without the buffer layer. The near band-edge emission consisting of free-exciton emissions and neutral-donor bound exciton emissions was significantly dependent on the buffer thickness and dominated by the free-exciton emissions in the layer grown on the very thin buffer layer about $0.8 \mathrm{~nm}$, whereas the intense emissions by neutral-donor bound excitons were observed in the $\mathrm{ZnO}$ layer on c-sapphire. The structural behavior indicated the donor was originated from the three-dimensional growth of $\mathrm{ZnO}$ layer and details of the optoelectronic feature suggested the residual donors were $\mathrm{Al}$ and interstitial- $\mathrm{Zn}$.
\end{abstract}

Keywords: $\mathrm{ZnO} ; \mathrm{Ti}_{2} \mathrm{O}_{3}$; Plasma-Assisted Epitaxy; Photoluminescence; Free-Exciton; Bound-Exciton

\section{Introduction}

$\mathrm{ZnO}$ is candidate for highly efficient blue or ultraviolet light-emitting devices using the wide direct band gap of $3.37 \mathrm{eV}$ and the large exciton binding energy of $60 \mathrm{meV}$ at room temperature. For such device applications, advanced processes are required for the high-quality growth and highly efficient impurity doping. To date, MBE using oxygen-plasma cell [1], MOMBE using $\mathrm{H}_{2} \mathrm{O}$ vapor [2], PLD [3] etc. have been attractively studied to improve the structural and optoelectronic properties. At the first stage for $\mathrm{ZnO}$ growth, reduction of oxygen deficiency which generates strong green-emission due to oxygen vacancies in $\mathrm{ZnO}$ had been required to improve the optoelectronic property. For the purpose, plasmaassisted epitaxy (PAE) using oxygen gas plasma was also an useful process as demonstrated for undoped- $\mathrm{ZnO}$ growth at the temperature as low as $400^{\circ} \mathrm{C}$ on c-sapphire $[4,5]$, in which the green-emission was sufficiently decreased comparing to the band-edge emissions. However, the near band-edge emissions were dominated by neutral donor bound emissions as same as the other processes, which indicated unexpected shallow donors were included with relatively high-density in the layer. It is important to prevent the donors during $\mathrm{ZnO}$ growth, espe-

${ }^{*}$ Corresponding author. cially for $\mathrm{p}$-type $\mathrm{ZnO}$ growth. Therefore, the origin and the removal process have been studied at the second stage, in addition to the effective acceptor doping into the layer $[6,7]$. As well recognized, low-temperature photoluminescence (PL) is so useful for evaluation of the impurities. In the case of $\mathrm{ZnO}$, the bound exciton emissions concerned with shallow donor impurities such as $\mathrm{Ga}, \mathrm{Al}$, In and $\mathrm{H}$ have been established with the free-exciton emissions [8]. In addition to such impurity donors, interstitial-Zn should also be taken into account for the shallow donor defect in $\mathrm{ZnO}$ as suggested by electron paramagnetic resonance [9]. In the growth process, the defect-donor can be easily introduced during three-dimensional growth of $\mathrm{ZnO}$ by high-sticking coefficient of $\mathrm{Zn}$-adatom at steps or kinks on the growth surface. Further, the unfavorable feature is probably enhanced in non-equilibrium growth at low temperatures required for highly efficient doping. Therefore, suitable two-dimensional $\mathrm{ZnO}$ growth at low temperatures with reducing impurity-donors and the intrinsic donor-defects is required for the optoelectronic device applications. For the purpose, we previously demonstrated drastic improvement of $\mathrm{ZnO}$ growth by $\mathrm{Ti}_{2} \mathrm{O}_{3}$ buffer layer on a-sapphire [10], where two-dimensional epitaxial growth of $\mathrm{ZnO}$ layer was successfully achieved without the rotational domain. 
In this paper, optoelectronic property of PAE-ZnO layer grown on the $\mathrm{Ti}_{2} \mathrm{O}_{3}$ buffer layer is examined by low-temperature photoluminescence and shows significant reduction of the residual donor. In addition, details of the near band-edge emissions suggest the donor species.

\section{Experimental}

\subsection{Layer Growth}

Titanium oxide layer was grown by LPCVD using titanium tetra-iso-propoxide (TTIP: Ti- $\left.\left(\mathrm{OC}_{3} \mathrm{H}_{7}\right)_{4}\right)$ and oxygen gas. Details of the apparatus and the condition was shown elsewhere [10]. In the case of buffer layer growth for $\mathrm{ZnO}$ layer, the thickness was controlled by the growth period estimated from the growth rate.

$\mathrm{ZnO}$ layer was grown at $340^{\circ} \mathrm{C}$ or $400^{\circ} \mathrm{C}$ in 3 mtorr by plasma-assisted epitaxy (PAE) using oxygen gas plasma generated by $10 \mathrm{~W}$ radio-frequency (rf) power at 13.56 $\mathrm{MHz}$ through a capacitively coupled rf-electrode. Details of the PAE-apparatus and the growth process were described elsewhere $[4,10]$. $\mathrm{ZnO}$ growth rate was different by change of the growth mode on c-, a- and the buffer layer as shown elsewhere [10], but effective $\mathrm{Zn} / \mathrm{O}$ supply ratio during the growth was kept at 1.0 by control of $\mathrm{Zn}$ flux determined by dependence of the growth rate on the Zn-flux.

Single crystalline a- and c-sapphire with mirror surface and $300 \mu \mathrm{m}$-thick were used as substrates after cleaning by organic-solvents and hot $\mathrm{H}_{2} \mathrm{SO}_{4}+\mathrm{H}_{2} \mathrm{O}_{2}$. In the case of etching, the substrates were treated in a hot $3 \mathrm{H}_{2} \mathrm{SO}_{4}+$ $\mathrm{H}_{3} \mathrm{PO}_{4}$ solution at $130^{\circ} \mathrm{C}$ for $15 \mathrm{~min}$.

\subsection{Evaluation}

Thickness of $\mathrm{ZnO}$ layers and $\mathrm{Ti}_{2} \mathrm{O}_{3}$ layers were checked by a contact-type surface profiler (Veeco, DEKTAK150). Surface morphology of the $\mathrm{ZnO}$ films was observed by Nomarski differential interference microscope (OLYMPUS, BX60). Optoelectronic property was examined by photoluminescence (PL) at $10 \mathrm{~K}$ using a cryogenic system (Janis Research, CCS-150). UV-light around $313 \mathrm{~nm}$ radiated from a deep UV-lamp (USHIO, UXM-501MA) was selected by a band-pass filter and irradiated on the $\mathrm{ZnO}$ layer through a sapphire window equipped on the cryostat chamber with the light power density about 2 $\mathrm{mW} / \mathrm{cm}^{2}$. The luminescent light modified to $20 \mathrm{~Hz}-\mathrm{AC}$ by an optical chopper was introduced into a monocrometor (JASCO, SS-50), then detected and amplified by a photomultiplier (Hamamatsu R374) driven by $1 \mathrm{kV}$. The current signal was amplified and converted to voltage signal by an amplifier (FEMTO, DLPCA-200), and then the noise components was removed in lock-in-amplifier (NF, LI5640) synchronous to the frequency by the chopper. Then, the signal was recorded in a $\mathrm{PC}$ after $\mathrm{A} / \mathrm{D}$ conversion. The relative sensitivity of the system for photon energy was corrected by black-body radiation spectrum from a standard lamp.

\section{Results and Discussions}

\subsection{ZnO Layer on C-Sapphire}

Growth rate of $\mathrm{ZnO}$ layers at $400^{\circ} \mathrm{C}$ (closed circles) and $340^{\circ} \mathrm{C}$ (open circles) on c-sapphire for various $\mathrm{Zn}$ flux in oxygen plasma excited by $10 \mathrm{~W}$ rf-power are shown in Figure 1. The growth rates same at both temperatures were increased with the Zn-flux then saturated by the flux above $80 \mu \mathrm{mol} / \mathrm{min}$. The results indicated the effective supply flux rate of $\mathrm{Zn} / \mathrm{O}$ could be determined at both temperatures since the growth rate was limited by smaller flux of $\mathrm{Zn}$ or O. Figure 2 shows typical near band-edge PL spectrum of PAE-ZnO layer with the thickness of $1.0 \mathrm{~m}$ grown at $400^{\circ} \mathrm{C}$ on c- sapphire by the $\mathrm{Zn} / \mathrm{O}$ supply ratio of 1.0 ( $\mathrm{Zn}$-flux: 80 $\mu \mathrm{mol} / \mathrm{min})$. The inset shows surface morphology of the layer observed by Nomarski microscope. The layer consisting of three-dimensionally grown columnar grains was preferentially oriented along c-axis but including $30^{\circ}$-rotational domains. In the PL spectrum, prominent emission peak at $3.3623 \mathrm{eV}$ originated from neutral donor-bound exciton emission (DBE) was observed with a weak DBE emission peak $3.3666 \mathrm{eV}$ and free-exciton emissions of $A-E_{x}$ and $B-E_{x}$ at $3.3774 \mathrm{eV}$ and around $3.385 \mathrm{eV}$ respectively [8]. FWHM of the DBE emission of the layer grown by the supply ratio around 1.0 was below $2 \mathrm{meV}$ and the intensity was 4orders magnitude larger than the green-emission due to deep-level. It is noted that the PL-spectrum was obviously degraded in the $\mathrm{ZnO}$ layer grown at temperatures lower than $400^{\circ} \mathrm{C}$ and the sharp near band-edge emissions could not be observed.

\subsection{ZnO Layer on $\mathrm{Ti}_{2} \mathrm{O}_{3}$ Buffer Layer}

\subsubsection{PL Spectrum on A-Sapphire and Buffer Layer}

Figure 3 shows near band-edge spectra of PAE-ZnO layers grown on (a) a-sapphire and (b) $\mathrm{Ti}_{2} \mathrm{O}_{3}$ buffer layer grown at $320^{\circ} \mathrm{C}$ with the thickness of $0.8 \mathrm{~nm}$, where the $\mathrm{ZnO}$ layers were grown at $340^{\circ} \mathrm{C}$ in oxygen plasma excited by $10 \mathrm{~W}$ rf-power. It is noted here the near bandedge emissions could be observed in $\mathrm{ZnO}$ layers grown at the temperature around $340^{\circ} \mathrm{C}$ but obviously degraded by the high temperature growth around $400^{\circ} \mathrm{C}$. The insets show the surface morphologies observed by Nomarski microscope. The layer was epitaxially grown on the buffer layer with the epitaxial relationship of [1-100] $\mathrm{ZnO} / /[1-100] \mathrm{Ti}_{2} \mathrm{O}_{3}$, whereas the layer was polycrystallized on a-sapphire. The hexagonal pyramid-like grains with the facets according to the epitaxial relationship as shown in the inset of (b) were observed in $\mathrm{ZnO}$ 


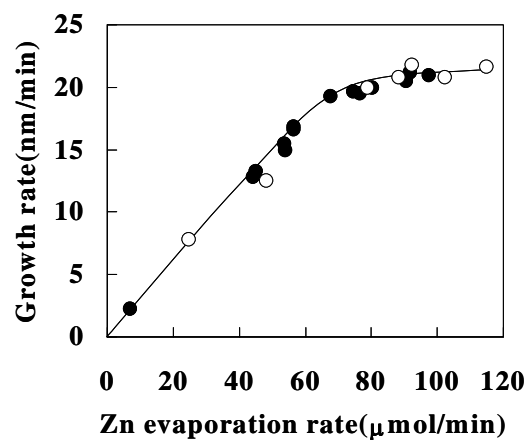

Figure 1. Dependence of $\mathrm{ZnO}$ growth rate on $\mathrm{Zn}$-flux, where the $\mathrm{ZnO}$ layers were grown on c-sapphire at $400^{\circ} \mathrm{C}$ (solid circle) and $340^{\circ} \mathrm{C}$ (open circle) in oxygen plasma excited by $10 \mathrm{~W}$ rf-power.

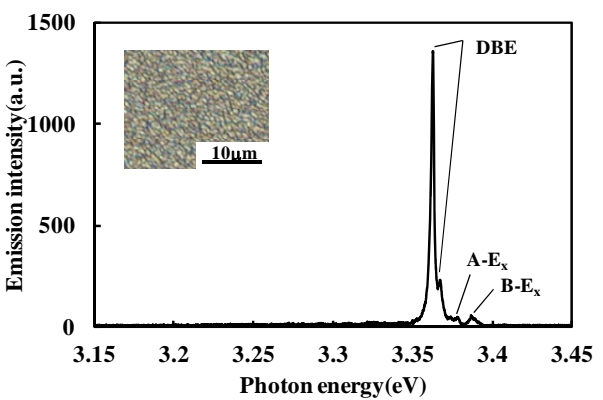

Figure 2. Photoluminescence spectrum of PAE-ZnO layer on c-sapphire.

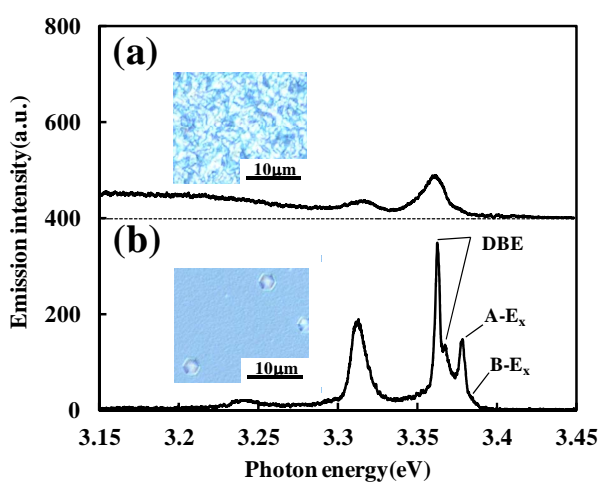

Figure 3. Photoluminescence spectra of PAE-ZnO layer on (a) c-sapphire and (b) $0.8 \mathrm{~nm}$-thick $\mathrm{Ti}_{2} \mathrm{O}_{3}$ /a-sapphire.

layer on the buffer layer, which indicated the two-dimensional growth was enhanced on the buffer layer as described elsewhere [10]. In the near band-edge PL-feature, strong and sharp exciton emissions could be observed from $\mathrm{ZnO}$ layer on the buffer layer, in contrast to board and weak emissions from poly-crystallized $\mathrm{ZnO}$ layer directly grown on a-sapphire. The spectrum of Figure 3(b) was dominated by DBE emissions with the same peak energies in Figure 2 (grown on c-sapphire), however, free-exciton emissions of $\mathrm{A}-\mathrm{E}_{\mathrm{x}}$ and $\mathrm{B}-\mathrm{E}_{\mathrm{x}}$ were clearly observed with decreasing the DBE intensities. The results indicate that although the $\mathrm{ZnO}$ layer was grown at low temperature comparing to the growth on csapphire, the crystallinity was improved on the buffer layer. In addition, the residual shallow donor could also be reduced in the $\mathrm{ZnO}$ on the buffer layer.

\subsubsection{Dependence on the Buffer-Layer Growth Condition}

The PL feature was significantly dependent on the growth condition and the thickness of buffer layer. Figure 4 shows variation of the intensity ratio of $A-E_{x}$ to $D B E$ emission peak at $3.3623 \mathrm{eV}$ on the thickness of buffer layer grown at $320^{\circ} \mathrm{C}$ and $340^{\circ} \mathrm{C}$ (closed circles) with the intensity of $\mathrm{A}-\mathrm{E}_{\mathrm{x}}$ emission (open circles). Crystal quality should not be discussed only by the intensity ratio because PL-spectrum is also influenced by non-radiative defects, but it can be considered the free-exciton emission intensity suggests the quality. In the case of $340^{\circ} \mathrm{C}$ growth of the buffer layer, $\mathrm{A}-\mathrm{E}_{\mathrm{x}}$ emission in $\mathrm{ZnO}$ layer on the $1.8 \mathrm{~nm}$-thick buffer layer was most intense, but optimized the thickness of buffer layer for the intensity ratio of $\mathrm{A}-\mathrm{E}_{\mathrm{x}} / \mathrm{DBE}$ was around $2.8 \mathrm{~nm}$ since not only the intense $A-E_{x}$ but also strong donor bound exciton emission were observed from $\mathrm{ZnO}$ layer on the $1.8 \mathrm{~nm}$ thick buffer layer. The result indicated non-radiative defects were significantly reduced in $\mathrm{ZnO}$ layer on the buffer layer with the thickness around $1.8 \mathrm{~nm}$ comparing to the $\mathrm{ZnO}$ layers on c-sapphire but the donor could not be reduced in the $\mathrm{ZnO}$ layer. In contrast, when the buffer layer was grown at $320^{\circ} \mathrm{C}$, the PL-property was more sensitive to the buffer layer thickness, but the thickness could be optimized at $0.8 \mathrm{~nm}$ for both of $\mathrm{A}-\mathrm{E}_{\mathrm{x}}$ intensity and the intensity ratio. The layer grown on the optimized buffer layer grown at $320^{\circ} \mathrm{C}$ showed smooth surface partially including hexagonal pyramid-like grains as shown in Figure 3(b), where the number of pyramidlike grain was most reduced in the $\mathrm{ZnO}$ layer on the optimized buffer layer [10]. It was found that the pyramid-like grains were originated from surface roughness and dislocations on a-sapphire and could be prevented by chemical etching of the substrate using a hot $3 \mathrm{H}_{2} \mathrm{SO}_{4}+$ $\mathrm{H}_{3} \mathrm{PO}_{4}$ solution. It is noted that density of the pyramidlike grains were decreased but columnar grains without the fine facets observed in the pyramid-like grains were increased with the buffer thickness above 2 and $4 \mathrm{~nm}$ for the growth temperature of $320^{\circ} \mathrm{C}$ and $340^{\circ} \mathrm{C}$, respectively.

\subsubsection{PL Spectrum of ZnO Layer on Optimized Buffer-Layer}

Figure 5 shows near band-edge PL-spectrum of $\mathrm{ZnO}$ layer on $0.8 \mathrm{~nm}$-thick buffer layer grown at $320^{\circ} \mathrm{C}$ on chemically etched a-sapphire. As shown in the inset, hexagonal pyramid-like grains were almost disappeared in the $\mathrm{ZnO}$ layer. In comparison to Figure 3(b), donor 


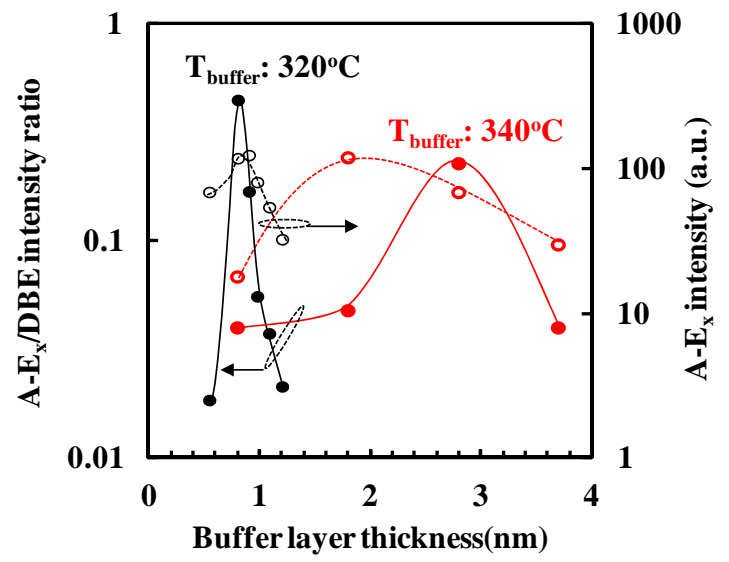

Figure 4. Dependence of $A-E x / D B E$ intensity ratio (closed circles) and $A-E_{x}$ intensity (open circles) on the thickness of $\mathrm{Ti}_{2} \mathrm{O}_{3}$ buffer layer grown at $320^{\circ} \mathrm{C}$ (black) and $340^{\circ} \mathrm{C}$ (red).

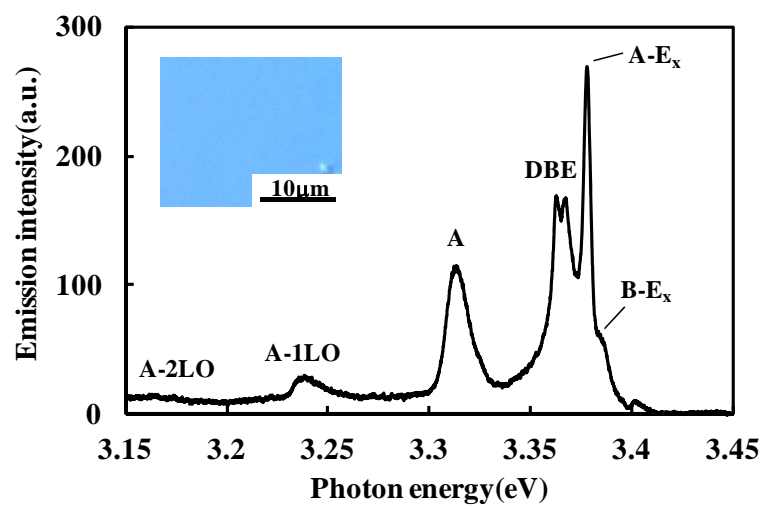

Figure 5. Photoluminescence spectra of PAE-ZnO layer on $0.8 \mathrm{~nm}$-thick $\mathrm{Ti}_{2} \mathrm{O}_{3}$ /a-sapphire, where the a-sapphire was chemically etched by a hot $3 \mathrm{H}_{2} \mathrm{SO}_{4}+\mathrm{H}_{3} \mathrm{PO}_{4}$ solution at $130^{\circ} \mathrm{C}$ for $15 \mathrm{~min}$ before the $\mathrm{Ti}_{2} \mathrm{O}_{3}$ growth.

bound exciton emissions were drastically decreased and dominated by intense and sharp A- $\mathrm{E}_{\mathrm{x}}$ with the FWHM below $5 \mathrm{meV}$. The fine feature clearly indicated residual donor was successfully reduced during the $\mathrm{ZnO}$ growth and the three-dimensional growth increased the donor density.

Broad-line around $3.313 \mathrm{eV}$ denoted "A", which was shifted between $3.313-3.315 \mathrm{eV}$ by the $\mathrm{ZnO}$ growth condition, with the photon-replicas (LO-phonon energy: $73 \mathrm{meV}$ ) was also observed in the $\mathrm{ZnO}$ layers. The emission was seemed to be similar to emission discussed as A-line [11], which was concluded as surface defectsrelated emission. The thermal activation energy of the broad-line obtained by Arrhenius-relationship on the intensity was about $60 \mathrm{meV}$, which indicated the emission was not due to electron recombination in deeplevel but originated from recombination of exciton bound to defects. Further, the emission was not observed from the $\mathrm{ZnO}$ layer on c-sapphire as shown in Figure 2, which indicated the emission was not derived from the grain boundaries. The origin of defect bounding exction is not identified yet, but may be related to surface structural defects $[11,12]$.

\subsubsection{Residual Donor}

It has been well recognized a lot of sharp donor bound exciton emission lines in the narrow energy range from 3.348 to $3.373 \mathrm{eV}$ [8], in which the lines are due to neutral or ionized donor defect pair $[8,13]$. Figure 6 shows PL spectra in log-scale of $\mathrm{ZnO}$ layers on (a) buffer layer and (b) c-sapphire. The bound exciton emission peak at $3.3623 \mathrm{eV}$ could be assigned to be due to neutral donor bound exciton with the localization energy of 15.1 $\mathrm{meV}$ from the $\mathrm{A}-\mathrm{E}_{\mathrm{x}}$ with peak at $3.3774 \mathrm{eV}$. Impurities corresponding to neutral donor bound exciton emissions have been identified in bulk- $\mathrm{ZnO}$ for IIIB-elements such as $\mathrm{Al}, \mathrm{Ga}$ and In [8]. Although peak energy of the neutral donor bound exciton emission was different from the impurity related bound exciton emission as previously reported, the localization energy of $15.1 \mathrm{meV}$ was coincident to the binding-energy of Al. The exciton line bound to hydrogen at $3.363 \mathrm{eV} \mathrm{[14]} \mathrm{was} \mathrm{in} \mathrm{agreement} \mathrm{to}$ the bound exciton in PAE-ZnO layer, but the impurity was rule out because the emission peak at $3.3623 \mathrm{eV}$ was not decreased by annealing at $600^{\circ} \mathrm{C}$ for 30 min whereas the emission bound to hydrogen-donor was drastically reduced by the annealing [14]. It is considered that the impurity can be identified by the localization energy from free-exciton emission because the free-exciton line is shifted by bi-axial stress [15]. The A-E $\mathrm{E}_{\mathrm{x}}$ emission of PAE-ZnO was shifted toward higher energy side than that with peak $3.3759 \mathrm{eV}$ (transversal free A-exciton state) dominated in A-exciton emissions bulk- $\mathrm{ZnO}$ [8]. As a result, it could be suggested that a residual donor in the PAE-ZnO layer was Al. Meyer, et al. showed Haynes'

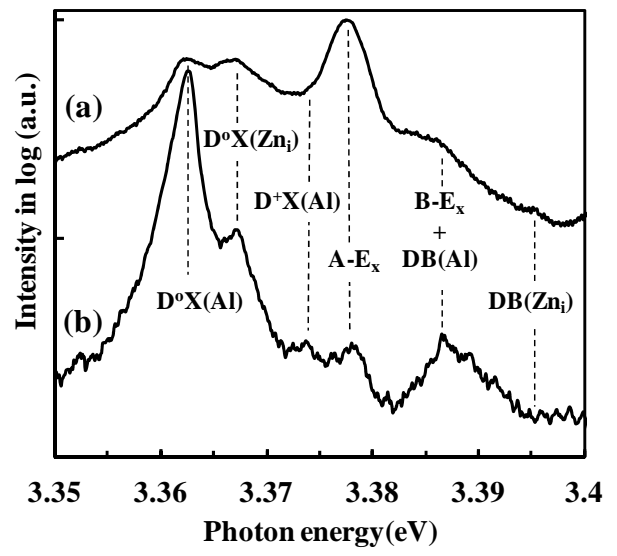

Figure 6. Photoluminescence spectra in excitonic emission region of PAE-ZnO layers on (a) 0.8 nm-thick $\mathrm{Ti}_{2} \mathrm{O}_{3} / \mathrm{a}$ sapphire and (b) c-sapphire, where the intensity was shown in log scale and the ground-line of (a) was shifted in vertical. 
rule in $\mathrm{ZnO}$ as $E_{\mathrm{loc}}=0.37 E_{\mathrm{D}}-4.2 \mathrm{meV}$ for neutral donor bound exiton and $E_{\mathrm{loc}}=0.50 E_{\mathrm{D}}-23 \mathrm{meV}$ for ionized donor bound exciton, where $E_{\text {loc }}$ and $E_{\mathrm{D}}$ are activation energy of donor and localization energy of the bound excitons from free A-exciton, respectively [16]. According to the localization energy of $15.1 \mathrm{meV}$ for the neutral donor bound exciton $\left(\mathrm{D}^{\circ} \mathrm{X}(\mathrm{Al})\right)$, binding energy of the donor was obtained as $52.2 \mathrm{meV}$. In addition, localization energy the ionized donor bound exciton $\left(\mathrm{D}^{+} \mathrm{X}(\mathrm{Al})\right.$ ) was expected to be at $3.1 \mathrm{meV}$ by the above relationship. The exciton line could be observed as the weak emission around $3.374 \mathrm{eV}$ on the low-energy side shoulder of the A- $E_{x}$ in (a) and at $3.3736 \mathrm{eV}$ in (b). Further, the donor to valence-band $(\mathrm{DB}(\mathrm{Al}))$ emission was expected to be observed at $3.3852 \mathrm{eV}$, in which the band-gap was obtained by the $A-E_{x}$ line and the binding energy of 60 $\mathrm{meV}$. It was difficult to identify the emission in PL spectrum because the emission line was overlapped on the B- $E_{x}$ emission, however, the intensity around $3.385 \mathrm{eV}$ in the spectrum with intense $\mathrm{D}^{\circ} \mathrm{X}(\mathrm{Al})$ emission was larger than that of $A-E_{x}$ emission as shown in Figure 6(b).

On the other, the donor concerned to the emission line at $3.3666 \mathrm{eV}$ with the localization energy of $10.8 \mathrm{meV}$ could not be identified by the IIIB-impurities. Previously, Shibata, et al. indicated the emission at $3.366 \mathrm{eV}$ is neutral donor bound exciton emission due to interstitial$\mathrm{Zn}$ [17], where the localization energy was obtained as $11 \mathrm{meV}$ because free-exciton emission was observed at $3.377 \mathrm{eV}$. The localization energy was in good agreement to that of the emission at $3.3666 \mathrm{eV}$ in PAE-ZnO. The spectral feature broader than the $\mathrm{D}^{\circ} \mathrm{X}(\mathrm{Al})$ also suggested the emission at $3.3666 \mathrm{eV}$ was due to exciton emission bound to interstitial-Zn complex $\left(\mathrm{D}^{\circ} \mathrm{X}\left(\mathrm{Zn}_{\mathrm{i}}\right)\right)$. Binding energy of the donor was obtained to $40.5 \mathrm{meV}$ and exciton will not be bound to the ionized donor with such shallow level $\left(E_{\mathrm{D}}<47 \mathrm{meV}\right)$ as recognized by the previous relationship [16]. In contrast, it is considered that the weak emission peak at $3.3955 \mathrm{eV}$ in Figure 6 (a) was the donor to valence-band emission $\left(\mathrm{DB}\left(\mathrm{Zn}_{\mathrm{i}}\right)\right)$, in which the donor binding energy was obtained as 41.9 $\mathrm{meV}$. It is noted that the emission of $\left(\mathrm{DB}\left(\mathrm{Zn}_{\mathrm{i}}\right)\right.$ was not observed from $\mathrm{ZnO}$ layer including $\mathrm{Al}$ with relatively high density as shown in Figure 6 (b).

Both of the $\mathrm{D}^{\circ} \mathrm{X}(\mathrm{Al})$ and $\mathrm{D}^{\circ} \mathrm{X}\left(\mathrm{Zn}_{\mathrm{i}}\right)$ were drastically reduced in the $\mathrm{ZnO}$ layer grown at $340^{\circ} \mathrm{C}$ on the buffer layer comparing to that on c-sapphire grown at $400^{\circ} \mathrm{C}$. The Al was probably diffused from sapphire substrate because the $\mathrm{D}^{\circ} \mathrm{X}(\mathrm{Al})$ was drastically reduced in the $\mathrm{ZnO}$ layer grown at $340^{\circ} \mathrm{C}$ on the buffer layer comparing to the layer on c-sapphire grown at $400^{\circ} \mathrm{C}$ although $\mathrm{Al}$ on the growth surface was expected to be with higher sticking coefficient at lower temperature. Therefore, two possible effects can be considered for reduction of the donor in $\mathrm{ZnO}$ on the buffer layer. The one is decrease of the growth temperature, which brings decrease of the diffusion coefficient. As expected increasing diffusion coefficient in grain boundaries, the other is concerned to structural behavior of $\mathrm{ZnO}$ layer, which can be expected by variation of $A-E_{x} / D^{\circ} X(A l)$ intensity ratio for the buffer layer thickness as shown in comparison to the growth behavior. That is, it is considered that the $\mathrm{Al}$ diffusion was suppressed in $\mathrm{ZnO}$ layer on the optimum buffer layer by significantly decreased grain boundaries. In contrast, interstitial-Zn is promised to be introduced on the surface during $\mathrm{ZnO}$ growth. Also in this case, it is expected that interstitial- $\mathrm{Zn}$ is easily introduced into the layer at low temperature, however, the $\mathrm{D}^{\circ} \mathrm{X}\left(\mathrm{Zn}_{\mathrm{i}}\right)$ was decreased by the buffer layer even at low temperature of $340^{\circ} \mathrm{C}$ comparing to $400^{\circ} \mathrm{C}$ for the growth on c-sapphire, which suggest that the surface structure is more important to prevent interstitial- $Z n$ than the growth temperature. Further, the intensity ratio of $\mathrm{A}-\mathrm{E}_{\mathrm{x}} / \mathrm{D}^{\circ} \mathrm{X}\left(\mathrm{Zn}_{\mathrm{i}}\right)$ of $\mathrm{ZnO}$ layer was drastically decreased on the buffer layer grown at $320^{\circ} \mathrm{C}$ with thickness above $1.2 \mathrm{~nm}$, where the threedimensional $\mathrm{ZnO}$ growth was drastically enhanced and a lot of columnar-grains without facets were observed, however, the increased ratio of $\mathrm{ZnO}$ layer including pyramid-like grains on the buffer layer with optimized thickness as shown in Figure 3(b) was similar to that of the layer successfully removed the grains by sapphire-etching as shown in Figure 4. The results indicate interstitial- $\mathrm{Zn}$ is increased on the three-dimensional growth surface but prevented on hexagonal pyramid surface.

\section{Conclusion}

Optoelectronic property of PAE-ZnO layers grown on c-sapphire, a-sapphire and $\mathrm{Ti}_{2} \mathrm{O}_{3}$ buffer layer was examined by PL at low temperature of $10 \mathrm{~K}$. Neutral donor bound exciton emissions were dominated in the near band-edge region of $\mathrm{ZnO}$ layer on c-sapphire. In contrast, although the PL feature was significantly dependent on the buffer layer thickness and the growth condition, successful reduction of donor bound exciton emissions by the optimized buffer layer were resulted in the spectrum dominated by free-exciton emissions. The residual donors in the $\mathrm{ZnO}$ layer could be identified as $\mathrm{Al}$ and interstitial-Zn by the localization energy of the neutral bound exciton emissions from free-exciton emission. The obvious decrease of grain boundaries in $\mathrm{ZnO}$ layer was so effective to the Al-reduction in addition to low temperature $\mathrm{ZnO}$ layer was nominally decreased by the low temperature growth of $340^{\circ} \mathrm{C}$ on the optimized buffer layer.

\section{REFERENCES}

[1] M. A. L. Johnson, S. Fujita, W. H. Rowland, Jr., W. C. Hughes, J. W. Cook, Jr. and J. F. Schetzina, "MBE Growth and Properties of $\mathrm{ZnO}$ on Sapphire and SiC Sub- 
strates," Journal of Electronic Materials, Vol. 25, No. 5, 1996, pp. 855-862. doi:10.1007/BF02666649

[2] A. B. M. A. Ashrafi, I. Suemune, H. Kumano and S. Tanaka, "Nitrogen-Doped p-Type ZnO Layers Prepared with $\mathrm{H}_{2} \mathrm{O}$ Vapor-Assisted Metalorganic Molecular-Beam Epitaxy," Japanese Journal of Applied Physics, Vol. 41, 2002, pp. L1281-L1284. doi:10.1143/JJAP.41.L1281

[3] R. D. Vispute, V. Talyansky, Z. Trajanovic, S. Choopun, M. Downes, R. P. Sharma, T. Venkatesan, M. C. Woods, R. T. Lareau and K. A. Jones, "High Quality Crystalline ZnO Buffer Layers on Sapphire (001) by Pulsed Laser Deposition for III-V Nitrides," Applied Physics Letters, Vol. 70, No. 20, 1997, pp. 2735-2737. doi:10.1063/1.119006

[4] S. Yamauchi, H. Handa, A. Nagayama and T. Hariu, "Low Temperature Epitaxial Growth of $\mathrm{ZnO}$ Layer by Plasma-Assisted Epitaxy," Thin Solid Films, Vol. 345, No. 1, 1999, pp. 12-17. doi:10.1016/S0040-6090(99)00096-6

[5] S. Yamauchi, T. Ashiga, A. Nagayama and T. Hariu, "Plasma-Assisted Epitaxial Growth of $\mathrm{ZnO}$ Layer on Sapphire," Journal of Crystal Growth, Vol. 214-215, 2000, pp. 63-67. doi:10.1016/S0022-0248(00)00060-9

[6] S. Yamauchi, Y. Goto and T. Hariu, "Photoluminescence Studies of Undoped and Nitrogen-Doped ZnO Layers Grown by Plasma-Assisted Epitaxt," Journal of Crystal Growth, Vol. 260, No. 1-2, 2004, pp.1-6. doi:10.1016/i.jcrysgro.2003.08.002

[7] D. C. Look, D. C. Reynolds, C. W. Litton, R. L. Jones, D. B. Eason and G. Gantwell, "Characterization of Homoepitaxial p-Type ZnO Grown by Molecular Beam Epitaxy," Applied Physics Letters, Vol. 81, No. 10, 2002, pp. 1830-1832. doi:10.1063/1.1504875

[8] B. K. Meyer, H. Alves, D. M. Hofmann, W. Kriegseis, D. Forster, F. Bertram, J. Christen, A. Hoffmann, M. Straßburg, M. Dworzak, U. Haboeck and A. V. Rodina, "Bound Exciton and Donor-Acceptor Pair Recombinations in ZnO," Physica Status Solidi (B), Vol. 241, No. 2, 2004, pp. 231-260.

[9] L. S. Vlasenko and G. D. Watkins, "Intrinsic Defects in
ZnO: A Study Using Optical Detection of Electron Paramagnetic Resonance," Physica B, Vol. 376-377, 2006, pp. 677-681. doi:10.1016/i.physb.2005.12.170

[10] S. Yamauchi and Y. Imai, "ZnO Heteroepitaxy on Sapphire Using a Novel Buffer Layer of Titanium Oxide: Crystallographic Behavior," Crystal Structure Theory and Applications, Vol. 2, No. 2, 2013, pp. 39-45.

[11] S. S. Kurbanov and T. W. Kang, "Spectral Behavior of the Emission Around $3.31 \mathrm{eV}$ (A-Line) from $\mathrm{ZnO}$ Nanocrystals," Journal of Luminescence, Vol. 130, No. 5, 2010, pp. 767-770. doi:10.1016/j.jlumin.2009.11.030

[12] A. Teke Ü. Özgür, S. Dogan, X. Gu, H. Morkoç, B. Nemeth, J. Nause, H. O. Everitt, "Excitonic fine Structure and Recombination Dynamics in Single-Crystalline ZnO," Physical Review B, Vol. 70, No. 19, 2004, Article ID. 195207-1-10.

[13] D. C. Reynolds, D. C. Look, B. Jogai, C. W. Litton, T. C. Collins, W. Harsch and G. Cantwell, "Neutral-DonorBound-Exciton Complexes in ZnO Crystals," Physical Review B, Vol. 57, 1998, pp. 12151-12155. doi:10.1103/PhysRevB.57.12151

[14] H. Alves, D. Pfisterer, A. Zeuner, T. Riemann, J. Christen, D. M. Hofmann and B. K. Meyer, "Optical Investigations on Excitons Bound to Impurities and Dislocations in ZnO," Optical Materials, Vol. 23, No. 1-2, 2003, pp. 3337. doi:10.1016/S0925-3467(03)00055-7

[15] B. Gil, "Oscillator Strengths of A, B, and C Excitons in ZnO Films," Physical Review B, Vol. 64, 2001, Article ID. 201310-1-3. doi:10.1103/PhysRevB.64.201310

[16] B. K. Meyer, J. Sann, S. Lautenschläger, M. R. Wagner and A. Hoffmann, "Ionized and Neutral Donor-Bound Excitons in ZnO," Physical Review B, Vol. 76, 2007, Article ID. 184120-1-10. doi:10.1103/PhysRevB.76.184120

[17] H. Shibata, M. Watanabe, M. Sakai, K. Oka, P. Fons, K. Iwata, A. Yamada, K. Matsubara, K. Sakurai, H. Tampo, K. Nakahara and S. Niki, "Characterization of ZnO Crystals by Photoluminescence Spectroscopy," Physica Status Solidi (C), Vol. 1, No. 4, 2004, pp. 872-875. 